\title{
Urgences
}

\section{Leurs mouvements}

\section{André Saint-Denis}

Numéro 20, mai 1988

Appellation contrôlée

URI : https://id.erudit.org/iderudit/025478ar

DOI : https://doi.org/10.7202/025478ar

Aller au sommaire du numéro

Éditeur(s)

Urgences

ISSN

0226-9554 (imprimé)

1927-3924 (numérique)

Découvrir la revue

Citer ce document

Saint-Denis, A. (1988). Leurs mouvements. Urgences, (20), 39-40.

https://doi.org/10.7202/025478ar

Ce document est protégé par la loi sur le droit d'auteur. L'utilisation des services d'Érudit (y compris la reproduction) est assujettie à sa politique d'utilisation que vous pouvez consulter en ligne.

https://apropos.erudit.org/fr/usagers/politique-dutilisation/
Cet article est diffusé et préservé par Érudit.

Érudit est un consortium interuniversitaire sans but lucratif composé de l’Université de Montréal, l'Université Laval et l'Université du Québec à Montréal. Il a pour mission la promotion et la valorisation de la recherche. https://www.erudit.org/fr/ 


\section{ANDRÉ SAINT-DENIS \\ Leurs mouvements}

à Marie Josée Thériault

Montréal, 6 mars 1938

Cher Monsieur,

Voilà. J'irai droit au but. Il n'est pas dans mes habitudes d'entreprendre ce genre de démarche, mais l'amitié, oui l'amitié, ici m'y oblige. Je me trouvais, il y a deux jours, en soirée, au bar de l'Hôtel de la Gare. C'est là que j' ai aperçu une femme dont la ressemblance avec la vôtre m'a frappé. Elle accompagnait un homme que je ne connais pas. Ils formaient, à eux deux, aux yeux de tous ceux qui s'étaient rassemblés dans ce bar, ce soir-là, le couple sur lequel les regards ne pouvaient pas ne pas s'attarder, au moins un peu. De leur table à la piste de danse, tous leurs gestes, tous leurs mouvements n'avaient de raison, semblait-il, qu'une sorte de folle invention amoureuse: comment allaient-ils s'embrasser, se toucher, se caresser dans les limites, disons, admises en de tels lieux... Encore qu'une fois ou deux j'ai pu croire que ces limites avaient été dépassées, de l'avis, au moins, des personnes qui m'entouraient. Je me répétais que cette femme ne pouvait être la vôtre. Je me le répète encore. Je dois bien admettre toutefois, ce soir en vous écrivant - c'est pour cela que je vous écris _, que je n'ai pas réussi à m'en convaincre.

Un ami 
Cher Monsieur,

Un mot pour vous transmettre mes condoléances les plus sincères. Le départ brutal de votre femme en aura attristé plus d'un. Je vous aurais écrit plus tôt, mais des obligations m'avaient conduit à l'extérieur de la ville et je n'ai appris la mauvaise nouvelle qu'à mon retour hier matin. Je revenais d'ailleurs à la maison avec l'intention, justement, de vous écrire pour vous signaler que j'avais revu la femme aperçue il y a quelques semaines à l'Hôtel de la Gare et qui me rappelait alors tellement la vôtre: à tel point que, je dois bien l'admettre maintenant, ma propre confusion aura été totale, vraiment, totalement ridicule. Preuve en est que, dans le train qui me ramenait hier matin à Montréal, le hasard a voulu que je me retrouve assis juste en face de cette afemme de l'Hôtel de la Garex; j'ai pu ainsi la regarder tout à loisir; la plupart de ses traits, oui, rappelaient bien vaguement ceux de votre femme (que Dieu ait son âme), mais un examen un tant soit peu attentif, une moins grande distance et un minimum d'éclairage permettaient facilement de dissiper tout malentendu, s'il en était. Aussi suis-je convaincu que vous garderez le meilleur souvenir de votre défunte épouse, d'autant qu'il ne sera pas entaché d'un quelconque doute, du genre de celui qu'auraient pu jeter sur elle (comme sur l'amour qu'elle vous portait) mes observations erronnées du début du mois.

Votre ami dans l'épreuve 